\title{
Teoria da decisão: o desenvolvimento do pensamento econômico da racionalidade à subjetividade $\star$
}

\section{Decision theory: the development of economic thinking from rationality to subjectivity}

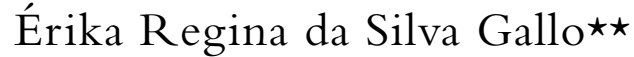

\begin{abstract}
Resumo: A teoria da decisão econômica se associa diretamente com alguns pressupostos amplamente conhecidos pela teoria econômica, como utilidade, racionalidade, maximização, análise de risco, entre outros. Entretanto, uma análise mais aprofundada sobre o desenvolvimento do pensamento econômico da teoria da decisão nos mostra que nem sempre os pressupostos descritos foram o mote dos estudos que buscaram compreender o comportamento decisório. Nesse sentido, o objetivo deste artigo é resgatar o desenvolvimento da teoria da decisão e seu desdobramento na chamada economia comportamental. A construção da narrativa apresentada foi apoiada na metodologia da história das ideias. $\mathrm{O}$ resultado deste trabalho sugere que ao longo dos séculos a teoria da decisão econômica transitou entre a subjetividade e a racionalidade como forma de explicar o comportamento de escolha econômica do indivíduo.
\end{abstract}

Palavras-chave: Teoria da decisão. Teoria econômica. Utilidade. Racionalidade. Economia Comportamental.

Abstract: The economic decision theory is directly associated with some assumptions widely known by economic theory, such as utility, rationality, maximization, risk analysis, it others. However, a more in-depth analysis of the development of economic thinking in decision theory shows that the assumptions described above were not always the motto of the studies that sought to understand decision-making behavior. In this sense, the objective of this article is to rescue the development of the theory of decision and its unfolding in the so-called behavioral economics. The construction of the presented narrative, it was supported by the

\footnotetext{
* Submissão: 16/09/2020 | Aprovação: 30/03/2021 | DOI: 10.29182/hehe.v24i2.768

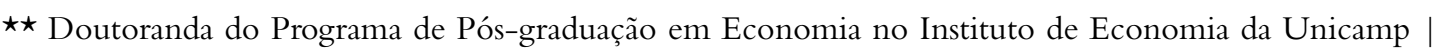
Brasil | E-mail: erika.reginagallo@gmail.com | ORCID: 0000-0002-1263-1390
}

Esta publicação está licenciada sob os termos de 
methodology of the history of ideas. The result of this work suggests, that over the centuries, the theory of economic decision has moved between subjectivity and rationality as a way of explaining the individual's economic choice behavior.

Keywords: Decision theory. Economic theory. Utility. Rationality. Behavioral Economics.

JEL: N01; B10; B21 


\section{Os jogos de azar e os primórdios da teria da decisão}

O interesse humano pelos jogos de azar é algo tão antigo que se confunde com a própria história da humanidade. Para os egípcios, gregos e romanos, os jogos de azar iam além de mera distração, eram um processo que envolvia competitividade. Na idade média, esse "passatempo" ganhou novos contornos e deu origem a diversos questionamentos humanos quanto à determinação de possibilidades (ganhos versus perdas; erros versus acertos), de previsibilidades, escolhas e tomadas de decisões.

Bernstein (1996) lembra que os jogos de azar, tão comuns na Idade Média, fazem surgir a vontade e a necessidade de previsão do futuro como forma de parametrizar as decisões. Ele ainda aponta que, na literatura, há indícios de que a própria teoria da probabilidade tem início a partir dos esforços mentais dedicados à previsibilidade do futuro que anseiam uma melhor tomada de decisão nas mesas de jogos.

O desenvolvimento da teoria da probabilidade e os posteriores progressos do cálculo probabilístico se devem a diversos estudiosos, dentre eles o monge franciscano Lucca Pacciolli, que publicou, em 1494, Summa de arithmetic, geometria et proportionalità, em que formulou o famoso "problema da divisão das apostas": "A e B estão empenhados em um honesto jogo de balla. Eles concordam em continuar até que um deles vença seis rodadas. $\mathrm{O}$ jogo realmente termina quando A venceu cinco, e B, três rodadas. Como devem ser divididas as apostas?" (David, 1962, p. 37).

Segundo Bernstein (1996), a solução desse problema de divisão de apostas marca o início da análise sistemática de probabilidade e o limiar da quantificação de risco e incerteza. A solução para esse problema foi alvo de estudo de diversos matemáticos, dentre eles o próprio Pacciolli, que sugeriu que a solução viria da divisão exata de partidas vencidas por cada jogador no momento em que o jogo é interrompido, ou seja, a aposta deveria ser dividida na proporção de 5 para 3 .

Outros importantes matemáticos sugeriram soluções para o problema da partilha de apostas, porém não lograram êxito. A solução definitiva apareceu por volta de 1652, quando esse problema foi colocado a Blaise Pascal pelo Chavalier de Mére, filósofo e grande entusiasta dos jogos de azar. Para responder ao enigma, Pascal iniciou uma série de correspondências com o também matemático Pierre de Fermat e juntos chegaram a uma conclusão satisfatória da problemática. Segundo Laplace (1814): "Ninguém, antes de 
Pascal e Fermat, estabeleceu os princípios e os métodos que permitissem calcular as chances favoráveis e desfavoráveis aos jogadores, bem como resolver questões complicadas deste gênero" (Laplace, [1814] 1988, p. 1304).

As conclusões a que chegaram Pascal e Fermat desembocaram em soluções distintas. Fermat baseou-se no cálculo da probabilidade de um evento ocorrer ou não, já Pascal baseou-se no conceito de valor esperado. ${ }^{1}$ Porém, mesmo distintas, as soluções eram equivalentes e marcaram o início da teoria da probabilidade. A partir de então, a probabilidade passou a ser ferramenta capital na análise do processo de escolha e de avaliação de risco dos indivíduos, tanto no âmbito das mesas de jogos de azar quanto em situações atualmente bem conhecidas, como, por exemplo: decisões de investimento produtivo, aplicações financeiras, entre outros eventos da vida humana.

Nesse sentido, este artigo é um esforço de pensar e organizar os desdobramentos teóricos que envolveram a formação da teoria da decisão dentro da economia. Para tanto, trataremos na seção 2 da criação de conceitos envolvendo a subjetividade ${ }^{2}$ humana em processos decisórios. Abordaremos o início do conceito de utilidade trazida por Bernoulli e seu desenvolvimento na teoria da utilidade esperada. Na seção 3 discutiremos os desdobramentos da teoria da decisão pelos economistas marginalistas e a tentativa de uma fundamentação teórica quantitativa da teoria da utilidade que passou a desconsiderar o papel da subjetividade humana e da incerteza, nos processos decisórios. Na seção 4 está será discutida a volta da incerteza nos processos decisórios e a tentativa heterodoxa de incluir a subjetividade humana como fator central na tomada de decisão. $\mathrm{Na}$ seção posterior, discutiremos o desenvolvimento da teoria neoclássica - a inclusão da incerteza como sendo algo mensurável no processo de escolha. Por fim, apresentaremos algumas das limitações da teoria da decisão econômica trazidas pela área de economia comportamental, juntamente com uma breve consideração final.

\footnotetext{
${ }^{1}$ A teoria do valor esperado ou esperança matemática pressupõe que apostas são avaliadas por seu valor esperado, ou seja, são avaliadas por uma média ponderada dos resultados possíveis, onde cada resultado é ponderado por sua probabilidade.

${ }^{2}$ Neste trabalho, a subjetividade se define no campo da psicanálise freudiana. Cujo conceito "subjetivo" se contrapõe ao conceito de "objetivo". Sendo o objetivo uma dimensão externa, material, coletiva, prática e a subjetividade uma dimensão interna, espiritual, individual, emocional. Essas definições são fundamentais para a análise psicanalítica, pois auxilia na discussão entre indivíduo e sociedade.
} 


\section{O processo decisório, a subjetividade humana e o conceito de utilidade}

A tomada de decisão é tema largamente debatido e estudado por diversas áreas do conhecimento, abarcando desde as ciências exatas, como a matemática e a estatística, assim como as ciências sociais, economia e psicologia. Essa temática torna-se tão instigante e debatida, não por ser própria de uma disciplina específica, mas por estudar o comportamento humano diante de uma situação de escolha; sendo assim, permite uma imensa variedade de análises.

Dentre os estudos ligados à área de conhecimento econômico, um dos primeiros trabalhos publicados que aborda a tomada de decisão é datado de 1738 e foi publicado na Commentari Academiae Scientiarum Imperialis Petropolitanae (Autos da Academia Imperial de Ciência de São Petersburgo) e intitulado Specimen theoriae novae de mensura sortis (Exposição de uma nova teoria sobre medição do risco). Esse ensaio escrito por Daniel Bernoulli baseia-se na observação da decisão dos mercadores de São Petersburgo ao adquirirem uma apólice de seguros para suas embarcações, tendo em vista possíveis perdas em trajetos mercantis.

Bernoulli (1738 [1954]) observou que, na realidade, a decisão tomada pelos mercadores pouco tem a ver com o proposto pela teoria do valor esperado - teoria que, até aquele momento, explicava a tomada de decisão mediante risco -, pois a teoria só explica os fatos, ignorando consequências de resultados possíveis para um indivíduo que toma decisão quanto a um evento futuro em um cenário de incerteza:

Desde que os matemáticos começaram a estudar a medição de risco, tem vigorado um consenso geral sobre esta proposição: os valores esperados são calculados multiplicando-se cada ganho possível pelo número de meios pelos quais pode ocorrer, e depois dividindo-se a soma desses produtos pelo número total de caso. (Bernoulli, [1738] 1954, p. 23)

Assim, para Bernoulli, o cálculo probabilístico não era suficiente para determinar o valor de algo, porque mesmo os fatos sendo iguais para todos, o efeito das consequências é subjetivo "depende das circunstâncias específicas de quem faz a estimativa. Não há razão para supor que os riscos estimados por cada indivíduo devam ser considerados de mesmo valor" (Bernoulli, [1738] 1954, p. 23).

O Quadro 1, exemplificado em Kahneman (2011, p. 341), mostra, de maneira clara, como Bernoulli desenvolveu a ideia de como a subjetividade 
humana impactava na tomada de decisão dos mercadores de São Petersburgo. Vejamos:

Quadro 1 - Riqueza versus Expectativa moral

\begin{tabular}{|c|r|r|r|r|r|r|r|r|r|r|r|}
\hline $\begin{array}{c}\text { Riqueza } \\
\text { (milhões) }\end{array}$ & 1 & 2 & 3 & 4 & 5 & 6 & 7 & 8 & & 9 & 10 \\
\hline $\begin{array}{c}\text { Expectativa moral } \\
\text { (unidade) }\end{array}$ & 10 & 30 & 48 & 60 & 70 & 78 & 84 & 90 & & 96 & 100 \\
\hline
\end{tabular}

Fonte: baseado em Kahneman (2011).

Aplicando o conceito de "expectativa moral", Bernoulli explica como e por que os mercadores de São Petersburgo tomavam a decisão de aquisição de apólice de seguro.

O Quadro 1 nos auxilia no entendimento do cálculo de quanto os mercadores estavam dispostos a pagar por um carregamento proveniente de Amsterdã, sendo que "era de conhecimento dos mercadores o fato de que, nessa época do ano, de cada cem navios que zarpavam de Amsterdã com destino a São Petersburgo, cinco normalmente se perdiam" (Kahneman, 2011, p. 342). Bernoulli, com sua função "expectativa moral”, explicou por que as pessoas com menor recurso financeiro compram seguro e por que pessoas com mais recursos financeiros vendem para elas. De fato, como pode ser observado no quadro, a perda de 1 milhão causa uma perda de 4 unidades de expectativa moral (de 100 a 96), para uma pessoa cuja riqueza é de 10 milhões e causa uma perda muito maior de 18 unidades (de 48 a 30) para uma pessoa cuja riqueza é de 3 milhões. Assim, o indivíduo de menor recurso financeiro pagará de bom grado um ágio para transferir o risco para um indivíduo mais rico (Kahneman, 2011, p. 341).

Nesse sentido, como resposta ao motivo pelo qual os mercadores adquirem apólice de seguros, Bernoulli propõe que nas decisões diante de uma situação incerta que envolve risco, os indivíduos tendem a atribuir valor à riqueza que possuem e que esperam ganhar, e que esse valor não é calculado simplesmente pelo valor monetário (valor financeiro dos ganhos), mas sim pelo que ele vai chamar de "valor moral" ou utilidade. Segundo Bernoulli ([1738] 1954):

[...] a determinação do valor de um item não pode ser baseada em seu preço, mas sim na utilidade que ele fornece. O preço de um item depende somente do próprio item e é igual para todo mundo; 
a utilidade, contudo, depende das circunstâncias particulares do indivíduo que faz a estimativa. (Bernoulli, [1738] 1954, p. 24, tradução nossa)

Dessa forma, o autor propõe que não é mais o valor absoluto (valor financeiro) que faz com que um indivíduo se decida em uma situação de decisão que envolve risco, mas o valor subjetivo (utilidade) que ele atribui para cada resultado. Tal valor subjetivo é, desse modo, "não a média ponderada de seus possíveis efeitos financeiros, mas sim a média da utilidade desses efeitos, cada qual ponderada segundo sua probabilidade" (Kahneman, 2011, p. 341).

A elaboração deste ensaio teve três objetivos principais:i) trazer o conceito de subjetividade na tomada de decisão; ii) mostrar que a aversão ao risco é proveniente de uma "expectativa moral" decrescente $;{ }^{3}$ iii) provar que a forma como os indivíduos medem os riscos e, por conseguinte, tomam decisões na vida real pouco tem a ver com a teoria do valor esperado. Segundo Bernoulli, a teoria do valor esperado era eficiente para medir resultados de jogos de azar, porém não explicava de maneira efetiva o comportamento dos indivíduos em uma situação real de escolha que envolve risco. Bernoulli explica que a teoria do valor esperado é falha porque tem como objetivo apenas os fatos e não leva em consideração possíveis incertezas que são latentes em um ambiente real de cotidiano. Ainda, segundo ele, as decisões estão sujeitas a particularidades individuais e de cenários, sendo assim, cada indivíduo vai estimar seu risco de acordo com sua contabilidade mental, fazendo com que cada decisão seja única.

Bernoulli possivelmente não sabia, mas estava cravando uma das pedras angulares da economia, o conceito de utilidade. E, embora o conceito de utilidade apresentado pelo autor seja ainda experimental e um tanto quanto intuitivo, marcado como uma "expectativa moral", um desejo ou uma satisfação, ele traz três ideias centrais para a teoria da tomada de decisão dos indivíduos:i) a satisfação (utilidade) está condicionada à subjetividade dos agentes; ii) os agentes atribuem ao risco valores diferentes, logo tomam decisões diferentes; iii) a satisfação (utilidade) resultante de uma elevação de riqueza será

\footnotetext{
${ }^{3}$ Observando o Quadro 1, podemos ver que: o incremento de utilidade (expectativa moral) de 1 milhão para 4 milhões é cinquenta unidades da riqueza, mas um incremento igual, de 4 para 7 milhões, aumenta a utilidade (expectativa moral) da riqueza em apenas 24 unidades. A utilidade (expectativa moral) da aposta é de $94 / 2=47$ (a utilidade de seus dois resultados, cada um ponderado segundo sua probabilidade de $1 / 2$ ). A utilidade de 4 milhões é sessenta. Como sessenta é maior do que 47, um indivíduo com essa função de utilidade (expectativa moral) preferirá a coisa segura (Kahneman, 2011).
} 
inversamente proporcional à quantidade de riqueza ou bens possuídos anteriormente. $^{4}$

A novidade da proposta de Bernoulli está no fato de que os resultados de uma decisão não estão somente na probabilidade dos fatos ocorrerem, mas também na subjetividade produzida pelo fator humano (como os fatores psicológicos e cognitivos, por exemplo) e de conjuntura que influenciam as decisões dos indivíduos e fazem com que cada agente tome decisões distintas.

Segundo Bernstein (1996), é a primeira vez na história da teoria da tomada de decisão envolvendo um cenário de risco e incerteza que é possível medir algo que até então não poderia ser mensurado - satisfação (utilidade). Ele diz:

Enquanto a teoria da probabilidade estabelece as opções, Bernoulli define as motivações das pessoas que optam. Essa é uma área de estudo e um corpo teórico totalmente novo. Bernoulli estabeleceu a base intelectual de muito do que se seguiria, não apenas em economia, mas em teoria sobre como as pessoas tomam decisões e fazem escolhas em todos os aspectos da vida. (Bernstein, 1996, p. 105, tradução nossa)

Conforme Bernstein (1996), a inovação mais ousada de Bernoulli é a ideia de que cada agente - mesmo os mais racionais - possuem um conjunto de valores únicos e tomam decisões segundo ele. Sendo assim, ao formular sua tese de que a utilidade é inversamente proporcional à quantidade de bens que um indivíduo possui, faz surgir uma visão fascinante sobre o comportamento humano e do modo como os indivíduos tomam decisões em face do risco e da incerteza.

Os conceitos tratados por Bernoulli foram essenciais para o avanço da teoria da decisão. Suas ideias repercutiram em diferentes áreas - economia, finanças, psicologia, entre outras - e derivaram diversas outras premissas importantes, principalmente para a economia no que tange à teoria da escolha do indivíduo. Assim sendo, o assunto tratado no próximo item é o desenvolvimento do conceito de utilidade na economia e como a subjetividade e a incerteza, fatores intrínsecos ao ser humano, passam a ser considerados problemáticos para uma ciência que procurava se aproximar das ciências exatas em busca de uma fundamentação teórica quantitativa.

\footnotetext{
${ }^{4}$ Esse postulado hoje é conhecido como "lei da utilidade marginal decrescente", que nos diz que, à medida que a riqueza aumenta, a utilidade adicional derivada do incremento da riqueza cai.
} 


\section{A tomada de decisão em um mundo normativo}

Era de se esperar que as contribuições de Bernoulli fossem ponto de referência para o desenvolvimento do que conhecemos hoje como teoria da utilidade esperada, visto que as ideias trazidas por ele quanto ao subjetivismo humano, aversão ao risco e o papel da incerteza na tomada de decisão, foram preceitos inovadores para a teoria da decisão de sua época.

Entretanto, não foi exatamente esse o caminho trilhado no desenvolvimento da teoria da utilidade.A maior parte da teoria de escolha dos agentes e o papel da incerteza no processo decisório, desenvolvidos dentro da teoria econômica, foram processos novos que durante uma parte da história econômica deixaram de lado a influência do fator humano, a presença da incerteza e o papel da conjuntura como sendo fundamentais em uma tomada de decisão. Assim, entre o final do século XIX e o início do século XX, a linha de pensamento econômico que dominou as discussões da teoria da utilidade (teoria da escolha do indivíduo) foi a dos chamados economistas marginalistas.

Os marginalistas foram na contramão dos pressupostos de subjetividade e incerteza trazidos por Bernoulli. Suas preocupações não estavam mais em analisar os fatores subjetivos - processos mentais e de valores morais que influenciavam os agentes em um processo decisório -, mas estavam focados simplesmente em analisar como os agentes tomavam decisões; isto é, a forma como aconteciam as decisões. Esse viés analítico mais objetivo fez surgir uma linha de pensamento e desenvolvimento da teoria econômica mais próxima da quantificação matemática.

Segundo Barbieri (2014), a "Revolução Marginalista" trouxe para a teoria econômica preocupações metodológicas quanto ao uso de métodos matemáticos. Esse período marca a sobreposição de duas revoluções metodológicas dentro da teoria econômica, a revolução formalista e a empirista. Ele diz:

\footnotetext{
A primeira revolução [formalista], aspecto particular da revolução marginalista de 1871, separa a economia verbal dos clássicos da economia expressa em termos matemáticos dos economistas neoclássicos. A segunda revolução [empirista], ocorrida na década de 1930, marca o abandono de uma perspectiva apriorística por um programa empirista, que demanda hipóteses econômicas empiricamente testáveis. (Barbieri, 2014, p. 6)
}

Os marginalistas foram fundamentais na formulação econômica neoclássica, sendo que diversos conceitos microeconômicos estudados ainda hoje, 
nas escolas de economia ao redor do globo, são originários desse período. A noção de racionalidade contrapondo-se à subjetividade em um processo decisório diante da incerteza é um desses preceitos que se perpetuam até a contemporaneidade. Se abstendo do subjetivismo que perpassa todos os agentes (as relações sociais, culturais, religiosas e emocionais), os teóricos marginalistas buscam, na matematização, criar padrões de comportamento normativos que seriam usados como "regras de bolso" pelos indivíduos no momento de tomar determinadas decisões.

Diferentes autores influenciaram o desenvolvimento teórico marginalista, dentre eles encontra-se o filósofo inglês Jeremy Bentham. Em sua publicação mais famosa, The principles of morals and legislation (Os princípios da moral e da legislação), publicada em 1789, o autor levanta questões importantes sobre o comportamento humano diante de uma situação de escolha. Segundo ele:

A natureza pôs a humanidade sob governo de dois senhores soberanos, a dor e o prazer. Cabe apenas a eles indicar o que deveríamos fazer, bem como determinar o que faremos [...] O princípio da utilidade reconhece essa sujeição e a pressupõe como fundamento daquele sistema, cujo objetivo é erigir a estrutura da felicidade pelas mãos da razão e da lei. (Bentham, 1871 apud Jevons, 1996, p 60)

Bentham foi essencial para o desenvolvimento da teoria da decisão como a conhecemos hoje, pois deixa claro que a razão é a chave para entender o comportamento humano. E que a satisfação - felicidade (utilidade) - pode ser entendida de maneira simplificada. Ora, se a dor e o prazer são iguais para todos os seres humanos, eis um primeiro padrão estabelecido. Quem, disposto de razão, preferiria a dor ao prazer? The principles of morals and legislation é considerada por muitos pesquisadores da área econômica como obra seminal da teoria neoclássica, pois levanta questões quanto à formação de preferências, processos decisórios e introduz os conceitos de maximização da utilidade e utilidade marginal. Para ele, a utilidade (satisfação) é a prioridade de qualquer ser humano e pode ser obtida por meio de qualquer objeto que tenda a produzir benefício, vantagem, prazer ou felicidade; ou então, que possa evitar a ocorrência de dano, sofrimento, mal ou infelicidade (Bentham, 1871 apud Jevons, 1996).

Desse modo, para o autor, a utilidade constitui um princípio essencial da ação humana em que o indivíduo tem como primazia a racionalidade autointeressada, ou seja, o indivíduo tem como principal característica a maximização de seus interesses e prazeres. Ele ainda diz que, em face de uma 
sociedade composta por um conjunto de indivíduos, basta que esses indivíduos entendam que a sociedade só tem a ganhar quando a maximização individual da utilidade (prazer) é efetuada (Dias, 2006).

As premissas comportamentais, assim como o conceito de indivíduo tratado por Bentham, influenciaram de maneira consistente a teoria econômica da era vitoriana no que tange ao estudo do processo de tomada de decisão. Seus conceitos foram base teórica para a formalização marginalista. Segundo Ferguson (1992), a historiografia do desenvolvimento marginalista pode ser dividida em três etapas: i) utilidade mensurável e aditiva (Gossen, Jevons e Walras); ii) utilidade mensurável e generalizada (Edgeworth, Antonelli e Fisher); iii) utilidade não mensurável e generalizada (a partir de Pareto). Sendo que na primeira fase, a utilidade seria mensurável em "útil"; na segunda, passa a contemplar os efeitos de complementariedade e substituibilidade entre os bens; e em terceiro lugar, representa apenas um ordenamento das preferências.

$\mathrm{Na}$ concepção teórica marginalista, os agentes decidem individualmente sobre quais bens e/ou serviços acreditam que lhes conferirão a maximização de sua utilidade - dada sua restrição orçamentária. Por serem racionais, os agentes têm perfeito conhecimento de suas preferências e das condições de mercado em que se encontram. Sendo assim, suas decisões são tomadas de maneira coerente, o que pressupõe um "padrão" racional. Na busca por gerar uma interpretação mais quantitativa, cria-se uma importante ferramenta de análise dos "padrões" de comportamento humano em situação de escolhas: a função utilidade. ${ }^{5}$ Assim, a utilidade (satisfação) passa a ser considerada como uma medida cardinal, ou seja, pode-se agora quantificar as preferências, prazeres, desejos e felicidade dos indivíduos.

Os marginalistas buscam na quantificação e na formulação matemática uma resposta à subjetividade do comportamento humano em situações decisórias. Nesse sentido, procuram uma fundamentação teórica quantitativa que pudesse estabelecer uma teoria do "valor-utilidade" e, assim, pudesse superar a antiga teoria do "valor-trabalho" dos economistas clássicos. ${ }^{6}$ Dentre

\footnotetext{
${ }^{5}$ Os marginalistas concebiam a função utilidade $\mathrm{U}\left(\mathrm{x} 1, \mathrm{x} 2, \ldots, \mathrm{x}_{\mathrm{n}}\right)$ como uma mensuração do bem-estar dos indivíduos, derivado do consumo de quantidades $x_{i}$ dos bens $i=1,2, \ldots, n$. Seguindo os pressupostos de Bentham, os marginalistas consideravam que quanto maior a quantidade de cada bem, maior o nível de utilidade - apesar da taxa de crescimento decrescente. Assim, a utilidade marginal era sempre positiva e decrescente (Cusinato, 2003).

${ }^{6}$ Em 1890, Marshall estabelece a teoria do valor neoclássica, sintetizando as teorias do valor-trabalho com a teoria do valor-utilidade pela criação das curvas de oferta e demanda.
} 
os marginalistas considerados pela historiografia econômica como os representantes da tentativa de uma fundamentação econômica mensurável e aditiva, podem ser citadas, como referência, as obras de Gossen ([1854], 1927), Jevons ([1871] 1996), Menger ([1871] 2007) e Walras ([1874] 1996).

Gossen, apesar de ter sido esquecido até 1871, tem um papel importante na teoria da escolha do indivíduo. Em sua obra, ele desenvolve conceitos como necessidade, satisfação e maximização. Ele era um defensor da utilização dos métodos matemáticos na teoria da escolha no que tange à maximização da satisfação humana. Para solucionar o problema da maximização, Gossen desenvolve o pressuposto de que a satisfação obtida de um consumo adicional de um determinado bem diminui progressivamente à medida que a quantidade consumida aumenta. Esse é um primeiro ensaio do que mais tarde conheceríamos como "Lei dos rendimentos marginais decrescentes" ou "Segunda lei de Gossen".

Carl Menger é considerado o fundador da Escola Austríaca. Uma das importantes contribuições trazidas pelo autor para a teoria da utilidade esperada é o conceito do indivíduo como o centro da estrutura econômica, que tem necessidades e que busca satisfazê-las - além da ideia de elencar necessidades. Segundo Menger, tendo o indivíduo recurso disponível para atender suas necessidades, ele irá elencar quais necessidades são mais importantes. Assim sendo, o indivíduo dispenderá seus recursos primeiramente para suas necessidades de primeira ordem e assim por diante, de modo que esse conceito é considerado um primeiro ensaio da utilidade ordinal que anos mais tarde seria tratada mais intensamente por Pareto.

Walras é considerado por muitos economistas como um dos mais brilhantes economistas da sua época. Suas contribuições para a teoria econômica neoclássica são importantíssimas. Sua contribuição metodológica mais importante é a separação entre a economia pura (perfeitamente científica propícia ao emprego de instrumentos matemáticos) da economia aplicada e social (que permite considerações de tempo e lugar e implica elementos morais). Com relação à utilização de métodos matemáticos em economia, Walras aponta:

Eu acho, de minha parte, que quando se trata de estudar os relatórios essencialmente quantitativos como são os relatórios de valor, o raciocínio matemático permite uma análise muito mais precisa, mais completa e mais rápida do que o raciocínio comum. (Walras, 1898, p. 67, tradução nossa) ${ }^{7}$

\footnotetext{
7 “Je crois, quant à moi, que, lorsqu'il s'agit d'étudier des rapports essentiellement quantitatifs comme sont les rapports
} 
Entretanto, como lembra Barbieri (2014), Jevons é, entre os autores marginalistas, o mais inclinado à quantificação, argumentando que a Economia, por ser uma disciplina que trata de quantidades, deveria ser expressa em termos matemáticos para que conseguisse atingir um maior rigor metodológico ${ }^{8}$. Jevons acreditava que "maximizar o prazer é o problema da economia" (Jevons, [1871] 1996, p. 69). Para ele, expressar a utilidade de uma maneira quantitativa tornaria vagas as generalidades subjetivas que caracterizavam a economia até aquele momento; "o prazer, a dor, o trabalho, a utilidade, o valor, a riqueza, o dinheiro, o capital, são todas noções que admitem a quantidade” (Jevons, [1871] 1996, p. 69). Ademais, Jevons trata a incerteza de maneira minimalista, ao declarar que "O teste da avaliação correta das probabilidades são os cálculos com relativa precisão em todos os assuntos corriqueiros da vida" (Jevons, [1871] 1996, p. 69). Segundo Bernstein (1997), Jevons minimiza a importância da incerteza no processo decisório, fazendo com que incerteza e risco se confundam e sejam tratados da mesma maneira: pela aplicação da probabilidade aprendida com observação de experiências passadas.

A busca por uma fundamentação quantitativa, matemática, para a teoria econômica chega ao extremo com Francis Edgeworth (1881) e seu hedonometer, que seria capaz de medir o "nível" de felicidade de cada indivíduo. A expressão em inglês, hedonometer, refere-se ao princípio hedonista. A reação hedonista baseou-se, de início, em um princípio unificado, já formulado por Gossen (1854). Este é: o homem busca sempre a satisfação com o mínimo de dispêndio e de esforço.

Segundo Edgeworth (1881), essa unificação inicial constitui uma abstração desejada e necessária. Desejada porque os hedonistas sabem e admitem a existência de muitos outros fatores móveis que explicam e provocam a atividade econômica do homem. Necessária porque com a fixação dos princípios hedonistas, em tais fatores moveis, é possível admitir a existência de traços de permanência e continuidade. Fazendo do hedonismo o motivo determinante mais importante e mais geral da atividade econômica.

Edgeworth achava indispensável admitir a abstração simplificadora do homo economicus, homem cuja ação se pressupõe orientada por um móvel psicológico único (Hugon, 1995). Ademais, Edgeworth também introduz o

\footnotetext{
de valeur, le raisonnement mathématique permet une analyse bien plus exacte, plus complète et plus rapide que le raisonnement ordinaire." (Walras, 1898, p. 67).

${ }^{8}$ Além dos autores já citados, considerável espaço também é dedicado à utilização de métodos matemáticos na economia nas obras de Marshall, Fisher, entre outros.
} 
conceito de curvas de indiferença, que mostram as possíveis combinações de bens e serviços que mantêm o consumidor no mesmo nível de bem-estar (Varian, 2006).

Não é dificil deduzir que tal instrumento foi alvo de diversas críticas que lograram espaço importante no debate econômico do final do século XIX e início do século XX. Entre as diferentes críticas direcionadas à quantificação marginalista, encontra-se a falta de clareza de como medir satisfação, prazer e felicidade. Segundo nos lembra Cusinato (2003), o ponto mais criticado pelos economistas pós marginalistas refere-se à tomada de decisão. Ora, dado que os agentes são maximizadores e racionais, se um indivíduo se defronta com duas opções de escolha, A e B (podendo ser essas: cestas de consumo, ou mesmo ativos financeiros), então a teoria nos diz que o agente decidirá pela opção que mais lhe trouxer satisfação (utilidade). No entanto, não há nenhuma "lei" ou evidência que prove que essa afirmativa é verdadeira. Em situações do cotidiano (na vida real), não há como o agente saber qual opção lhe conferirá maior felicidade ou prazer. Digamos, por exemplo, que um agente se defronte com duas opções de ativos (ativo A e ativo B), e esse agente, usando de toda sua capacidade maximizadora e racional, decide-se pelo ativo B; no entanto, o ativo A poderia ser a melhor escolha ou realmente $\mathrm{B}$ poderia ter sido a melhor escolha. $\mathrm{Na}$ verdade, não há como saber.

Existem dois problemas fundamentais nesse ponto, que os marginalistas não levaram em consideração: i) os pressupostos de maximização e racionalidade não levam em consideração possíveis riscos, aversões e incertezas que cada agente pode carregar intrinsicamente no seu ser; ii) nem todas as escolhas são baseadas em previsões futuras derivadas do cálculo probabilístico - o consumo de um bem é um exemplo claro dessa afirmativa. Ora, hoje eu posso tomar sorvete de flocos e amanhã escolher de morango, tais escolhas nada tem a ver com probabilidade. Ademais, não fica claro como a utilidade poderia ser medida. Como é possível medir a satisfação individual? Como é possível medir a felicidade?

Não foram poucos os críticos da metodologia marginalista quantitativa. Entre os diversos críticos encontram-se Vilfredo Pareto ([1906] 1996) e sua crítica à quantificação da utilidade; Frank Knight ([1921] 1964) e John Maynard Keynes (1936), que trouxeram imensurável contribuição, por meio da inserção da incerteza na tomada de decisão, e Hicks e Allen (1934), que buscam uma indexação matemática à teoria da utilidade.

Após a revolução marginalista, toma corpo nova proposta de funda- 
mentação teórica: a matemática sem número. Segundo Barbieri (2014, p. 7): "A influência [da matemática sem número] se estende até a década de 1930 e sobrevive até mais tarde em autores heterodoxos". Ainda segundo o autor, é a partir da década de 1930 que há uma segunda revolução metodológica, que associa o caráter científico da teoria econômica com a capacidade de teste empírico das hipóteses. Ele diz:

Diante dos problemas do positivismo e da dificuldade imposta pelo fato de que, no que diz respeito a fenômenos complexos, a adoção de hipóteses com maior conteúdo empírico seria automaticamente refutada, surgem metodologias como o empirismo lógico, o operacionalismo e o instrumentalismo, que valorizam um conceito pela sua capacidade de gerar consequências testáveis, deslocando assim o foco da análise científica da explicação para a previsão. (Barbieri, 2014, p. 8)

Porém, ainda no início do século XX, Pareto ([1906] 1996), ao questionar a utilidade cardinal e os pressupostos maximizadores da felicidade, traz relevantes contribuições para a teoria econômica. O autor, partindo da concepção de curva de indiferença tratadas por Edgeworth, elabora uma abordagem ordinal para a utilidade. Ao notar que as curvas de indiferença representavam combinações de cestas de consumo que maximizavam a utilidade dos agentes, ele observou que quando se quantificava a felicidade por meio da combinação das cestas de consumo, a função-utilidade dessa combinação atribuía um "número maximizador" dessa combinação que fundamentalmente elencava, ou seja, ordenava, essas cestas de consumo.

Essa observação talvez tenha sido a de maior expressão quanto à colaboração de Pareto na teoria da escolha. Ao ordenar as combinações das cestas, o autor mostra que não era necessário saber "quanto", mas em que "ordem" a maximização da utilidade é alcançada. Segundo Cusinato (2003, p. 27), "com a ordenalidade, tudo que era necessário era um indexador de ordenação que designasse um número para cada cesta de consumo”. Sendo assim, para as cestas que tivessem um nível maior de utilidade dava-se um número mais alto, e para as cestas que fornecessem níveis inferiores de utilidade dava-se números menores. Dessa forma, a função utilidade de cada item é distinta, mas fornece o mesmo ordenamento; logo, elas são equivalentes sob a ótica ordinalista.

Entretanto, como nos lembra Bernstein (1997), mesmo após a publicação da teoria da utilidade ordinal de Pareto, o pressuposto cardinal permaneceu 
como teoria dominante entre os autores neoclássicos; somente após a década de 1930 o pressuposto de mensuração da utilidade sucumbe diante da ordinalidade proposta por Pareto.

Na década de 1930, Hicks e Allen (1934) dão início à "moderna teoria da utilidade". Segundo essa interpretação, a utilidade não é a causa das preferências, mas uma descrição das preferências. Os indivíduos não escolhem tendo por base uma função de utilidade, mas escolhem o que preferem. Independentemente dos processos psicológicos que os indivíduos empregam no processo de escolha, a utilidade é apenas uma indexação matemática para descrever o que eles preferem. Não é o indivíduo que deve se comportar segundo sua função-utilidade, mas é a função-utilidade que deve emular o comportamento de escolhas do indivíduo. De acordo com Cusinato (2003), prazer, felicidade e satisfação tornam-se irrelevantes para a abordagem moderna da teoria de utilidade.

Contudo, mesmo com os avanços propalados pela ordenação da utilidade, a tomada de decisão em cenários de incerteza continuava ponto obscuro na teoria econômica da escolha dos indivíduos. O processo decisório sob incerteza continuava uma esfinge que todos os economistas à época sabiam que existia, mas pouco se havia desenvolvido nessa direção desde Bernoulli. Somente após publicações de Knight e Keynes, em uma linha mais heterodoxa, passou-se a discutir o papel da incerteza na tomada de decisão dos agentes. Posteriormente, em 1944, John Von Neumann e Oskar Morgenstern, utilizando-se dos pressupostos da teoria neoclássica, desenvolveram padrões de comportamento dos agentes para a teoria da utilidade esperada e trouxeram à luz da discussão o papel da incerteza nos processos decisórios.

As premissas de Knight e Keynes, bem como os pressupostos de Neumann e Morgenstern, serão os assuntos tratados nas próximas seções.

\section{As decisões e a incerteza}

Como lidar com processos decisórios que não se explicam por um conjunto de probabilidades pré-estabelecidas? Ou então, quando a teoria dominante não consegue explicar as tomadas de decisões dos agentes? $\mathrm{E}$ quando as escolhas menos prováveis são as que se apresentam com maior frequência no mundo real? Ou ainda, quando os acontecimentos passados não ajudam a prever os eventos futuros?

Esses são alguns dos questionamentos levantados por Knight ainda na 
década de 1920, e que, posteriormente, também foram tratados por Keynes na década de 1930. Mesmo os dois autores não tendo trabalhado em conjunto, nem tendo desenvolvido nenhuma parceria acadêmica ou científica, eles individualmente foram os primeiros economistas do século XX a colocarem tais questões em pauta na teoria da decisão.

Knight foi um inconformado e ruidoso contestador da racionalidade dos agentes. Para ele, o pressuposto de preferências perfeitas era incoerente com a realidade humana; logo, tentar desenvolver uma teoria que padronizasse o comportamento dos indivíduos era algo que não traria nenhuma contribuição efetiva para a teoria econômica. Este autor pouco acreditava que o cálculo probabilístico pudesse refletir a diversidade do comportamento humano em situações de escolhas. $\mathrm{O}$ fato de a probabilidade matemática estar diretamente associada à coleta de um número grande de observações passadas - como forma de gerar padrões de comportamento - fornecia, segundo o autor, indícios de que essa metodologia era alvo de questionamentos, afinal "nenhum evento é idêntico ao outro e a vida é curta demais para os indivíduos conseguirem agrupar amostras suficientes para gerar padrões que possam auxiliar em uma tomada de decisão" (Knight, 1921,p. 196). Ele dizia:"Qualquer 'ocorrência' [...] é tão inteiramente singular que não há outros ou um número suficiente que permita tabular ocorrências iguais o bastante para formar uma base para qualquer inferência de valor sobre quaisquer probabilidades reais." (Knight, 1921, p. 197).

Porém, provavelmente a contribuição mais importante de Knight para a teoria da escolha não tenha sido o questionamento da racionalidade, mas a distinção entre risco e incerteza. Para o autor, risco é uma probabilidade mensurável enquanto a incerteza é uma situação de valores indeterminados e não quantificados. Para ele:

\footnotetext{
A incerteza deve ser tomada em um sentido radicalmente distinto da noção familiar de risco, da qual nunca foi apropriadamente separada [...] Descobrir-se-á que uma incerteza mensurável, ou "risco" propriamente é tão distante de uma imensurável que, na verdade, não chega a ser incerteza. (Knight, 1921, p. 205, tradução nossa)
}

Knight baseia sua discussão sobre o conceito de incerteza na teoria de determinação do lucro pois, segundo ele, os lucros estão inseridos dentro de um cenário de incerteza. O lucro é um resquício, que não pode ser determinado de maneira exata a priori, ou seja, seu total só se torna real em uma 
data posterior à tomada de decisão. Desse modo, os processos de julgamentos formados pelos agentes (como, por exemplo, a formação de expectativas) e a própria incerteza dos eventos futuros, acarretarão impactos diretos no montante de lucro, de modo a torná-lo imensurável.

Knight vai dizer que, em uma situação decisória, os agentes fazem uma estimativa do que esperam ganhar após uma tomada de decisão de investimento. Para ele, a estimativa é um tipo de probabilidade, mas não uma probabilidade empírica; seria uma probabilidade intuitiva que norteia o agente no processo de escolha.Ainda, "os agentes se baseiam em estimativas não inferenciais, isto é, baseiam-se em julgamentos ou intuições e não em raciocínio estritamente lógico e probabilístico" (Knight, 1921, p. 223, tradução nossa).

Portanto, as decisões cotidianas, em especial as pertinentes ao investimento, estão relacionadas a situações singulares, únicas, que não podem ser preditas de maneira exata:"uma probabilidade objetivamente mensurável não é aplicável” (Knight, 1921, p. 231, tradução nossa).

Segundo Bernstein (1996), as ideias de Knight auxiliam na explicação, por exemplo, do movimento do mercado financeiro, onde a formação de expectativa é processo intrinsicamente presente e a tomada de decisão reflete uma "previsão" do futuro. Segundo Bachalier:"Claramente, o preço considerado mais provável pelo mercado é o preço atual real: se o mercado julgasse de outra forma, não fixaria esse preço, mas outro preço superior ou inferior" (Bachalier apud Bernstein, 1996, p. 221).A volatilidade dos preços dos títulos e das ações são reflexos das frustações das expectativas dos investidores. Sendo assim, "a volatilidade é uma representante da incerteza que normalmente é acomodada na avaliação de risco do investidor" (Bernstein, 1996, p. 221, tradução nossa).

A formação de expectativa em Knight é, portanto, comum no mercado financeiro, onde tantas tomadas de decisões dependem das "previsões" de futuro, dado que os agentes tendem a identificar os momentos críticos somente depois desses momentos já terem ocorrido. Ora, se os agentes fossem capazes de identificar de maneira perfeita, clara e objetiva as futuras mudanças que iriam ocorrer no mercado de capitais, não haveria mudanças abruptas, não haveria volatilidade alguma. A presença do fator "incerteza" no mercado de capitais - e em tantos outros mercados da esfera econômica - é a prova de que a probabilidade matemática não é capaz de munir os agentes de certeza alguma, somente oferece uma ferramenta de minimização de risco. 
Keynes também analisou a presença da incerteza nas decisões dos agentes e foi além. Ofereceu fundamentação teórica para análise da presença da incerteza tanto nas decisões dos agentes quanto nos impactos dessas decisões sob incerteza em diferentes mercados.

O autor trata das decisões diante da incerteza em duas publicações clássicas:i) no livro Teoria geral (Keynes, 1936), capítulo XII:"O estado da expectativa de longo prazo"; ii) e no artigo "A teoria geral do emprego" (Keynes, 1937).

Ao tratar a incerteza, no capítulo XII, Keynes aborda preceitos que antes não haviam sido considerados pelos economistas que estudavam a tomada de decisão dos agentes, a saber: o papel da incerteza nos processos decisórios, o impacto dos processos decisórios individuais na esfera econômica; e, ainda, questiona a metodologia quantitativa na economia.

Ele observa que os temas incerteza e tomada de decisão estão em um "nível diferente de abstração", o que implica dizer que o estudo teórico econômico necessitava de uma abordagem mais ampla do que a quantificação matemática podia oferecer. Ainda na mesma obra, o autor explica que a tomada de decisão depende da formação de expectativa corrente e futura dos agentes - sendo a última afetada diretamente pela primeira. Assim, as expectativas futuras dependem dos eventos correntes que os agentes acreditam conhecer - com maior ou menor intensidade de certeza, como, por exemplo, o volume de ativos existente no mercado imobiliário (Keynes, 1936). Para ele, as expectativas podem ser divididas, e entendidas, de duas formas: i) expectativa de longo prazo - que se refere ao estado de expectativa psicológica (formação de expectativas para o futuro); e ii) expectativa de curto prazo - que está relacionada a prognósticos de receitas e de comercialização, por exemplo.

Quanto à formação de expectativa de longo prazo, Keynes (1936) aponta que ela está sujeita à influência do estado atual das coisas, quer dizer, a menos que alguma situação ocorra, os agentes permanecerão "acreditando" em sua formação de expectativas e continuarão projetando seu futuro com base nessas expectativas formadas. Sendo assim, as decisões de investimento dependem do "estado de expectativa de longo prazo". Portanto, dependem da formação de um prognóstico de futuro e da confiança que os agentes empenham nessa formulação. Pode-se dizer que o grau de confiança presente nas decisões dos agentes está intimamente atrelado ao grau de incerteza do futuro percebido (Keynes, 1936). 
A incerteza em Keynes está profundamente ligada ao conhecimento de particularidades do cenário futuro, que sabidamente é fato impossível de ser previsto. Portanto, é igualmente impossível ser expressa em termos matemáticos probabilísticos. Sempre haverá situações em que o imprevisível acontecerá; algo sempre pode acontecer e, consequentemente, afetar o rumo dos eventos previstos e não há nenhum meio de descobrir essas particularidades. Em todas as decisões tomadas, há algum nível de incerteza, mesmo que os agentes tenham baseado suas decisões no universo conhecido. Os agentes sempre terão que lidar com o desconhecido e com o incerto: " $\mathrm{O}$ conhecimento é sempre vago, flutuante e incerto" (Keynes, 1937, p. 113, tradução nossa). Assim, a análise de Keynes enfatiza a inalcançável capacidade cognitiva humana em prever eventos futuros, e, devido ao curso natural da economia, sempre haverá um hiato entre a tomada de decisão e os resultados conhecidos. E, desse hiato, sempre nascerá a incerteza quanto aos eventos passíveis de ocorrerem.

A discussão sobre a presença da incerteza nos processos decisórios e suas implicações na esfera econômica não acabaram com Knight e Keynes; eles apenas deram início a uma marcha que perdura até hoje. No entanto, alguns de seus diversos seguidores também fizeram escola e se destacam na discussão do papel da incerteza na tomada de decisão, dentre eles podemos citar Shackle e Davidson.

Shackle (1965), assim como Knight e Keynes, aponta a incerteza e o risco como sendo conceitos distintos. Para ele, o conceito de incerteza está diretamente ligado à ausência do conhecimento e seria, portanto, algo impossível de ser mensurado por distribuições probabilísticas. Segundo o autor, decisões baseadas em probabilidades são falhas, visto que nenhum experimento (por maior que seja o tamanho da amostra) conseguirá prever eventos futuros, pois não há meios de prever a trajetória que os acontecimentos seguirão. Desse modo, o agente sempre se deparará com eventos desconhecidos, incertos, que não podem ser previstos matematicamente.

A inovação da proposta de Shackle está na análise do comportamento dos agentes em dois ambientes distintos: i) ambiente de ordem - onde os agentes podem "imaginar" eventos futuros, ou seja, podem formar expectativas (quanto à ordem dos eventos, o movimento dos demais agentes que operam naquele mercado, por exemplo) e acreditar que elas se concretizarão; ii) ambiente de inspiração - nesse, o agente deve dar espaço para o "processo criativo" e deve aceitar que os eventos são incertos e que não há como 
prever de maneira efetiva os eventos futuros. Portanto, ao lançar o preceito de "processo criativo", Shackle abre discussão para a heterogeneidade dos agentes, em que a inspiração (ou a criação humana) quebra com o preceito de ambientes predeterminados, nos quais todos os elementos podem ser previstos.Assim, a tomada de decisão "criativa/inspirada" não pode ser prevista e, por não seguir padrão, tem a capacidade de alterar os resultados futuros intrinsicamente (Shackle, 1990).

Davidson (1983), de forma similar a Shackle, mantém o pensamento heterodoxo de Knight e Keynes quanto ao comportamento dos agentes e a incapacidade probabilística em previsão do futuro. Sua inovação está na elaboração de dois cenários distintos onde ocorreriam os processos decisórios, a saber: os cenários ergódico e não ergódico.

Segundo o autor, em um cenário ergódico, o presente e o futuro são imutáveis, sendo passíveis de serem previstos por uma distribuição de probabilidade. Já em um cenário não ergódico, os eventos são aleatórios, distintos, passíveis de serem alterados e, portanto, impossíveis de serem previstos por probabilidade ou matemática. A incerteza permanece sendo a ausência do conhecimento; assim, estaria presente em cenários não ergódicos, que podem ser entendidos como sendo eventos cotidianos, da vida real (Davidson, 1995).

A incerteza permanece sendo conceito importante estudado na economia e nas finanças; porém, após publicações de Knight e Keynes, duas linhas de estudos se distinguem, a incerteza como sendo algo imensurável, longe da quantificação matemática e da distribuição de probabilidade, e a incerteza neoclássica, que progrediu a partir de estudos de meios de quantificação, "matematização" e criação de padrões de comportamento que oferecem diretrizes na tomada de decisão em face da incerteza.

Não são poucos os pesquisadores que se debruçaram sobre o conceito de incerteza na economia, de modo que podemos citar alguns trabalhos contemporâneos: Lawson (1997), Carvalho (1998), Runde (1990,1991,1995), Vercelli (1995, 2002), Dequech (1997, 2000, 2004, 2007). Em todos esses trabalhos, mesmo os autores abordando o assunto de diferentes perspectivas, permanecem tendo em comum alguns pontos:i) a incerteza é fruto da ausência do conhecimento dos eventos futuros; ii) não é possível tomar decisões baseando-se em eventos passados; e iii) a estimativa probabilística não consegue abranger as mudanças conjunturais que ocorrem entre a tomada de decisão presente e a efetivação futura. 


\section{Tomada de decisão pela ótica da racionalidade}

Talvez o matemático John Von Neumann e o economista Oskar Morgenstern tenham sido os autores neoclássicos que mais contribuíram para o desenvolvimento da teoria da utilidade esperada no que tange aos processos decisórios em face da incerteza e do risco. A publicação de maior destaque de ambos, Theory of games and economic behavior de 1944, é um marco para a teoria neoclássica, visto que a partir dela foram geradas diversas ramificações teóricas - tanto dentro da economia quanto em outras áreas correlacionadas - sobre o papel das tomadas de decisões dos agentes e o impacto que essas decisões poderiam causar no ambiente onde ocorreriam. Ao trazerem alguns preceitos já tratados por Bernoulli ([1738] 1954) - como:"quão longe estamos dispostos a ir na tomada de decisão que possamos provocar os outros a tomar decisões que terão consequências adversas para nós?" -, eles trazem de volta para a discussão da escolha todo o rigor da racionalidade clássica, expondo com clareza o conceito de preferência e a forma como esta deveria ser metodicamente aplicada (Bernstein, 1996).

Os autores desenvolvem um "padrão" para o comportamento dos indivíduos (isto é, axiomas) que são utilizados para fornecer respostas quanto às escolhas dos agentes econômicos. Por rejeitarem os pressupostos da subjetividade do comportamento humano em processos decisórios (tal qual a formação de expectativas keynesianas) que impediam a aplicação dos métodos matemáticos, eles reafirmam a aplicação quantitativa como formalização metodológica. Segundo Von Neumann:

[...] para se construir uma ciência da fisica, esse fenômeno [calor e luz] teve de ser medido. Subsequentemente, os indivíduos passaram a usar os resultados de tais medições (direta ou indiretamente) mesmo na vida cotidiana. O mesmo poderá acontecer na economia no futuro. Uma vez alcançada uma compreensão mais plena do comportamento humano com a ajuda de uma teoria que faça uso de medição, a vida do indivíduo poderá ser materialmente afetada. Esses problemas não constituem, portanto, uma divagação desnecessária. (Von Neumann; Morgenstern [1944] 1980, p. 3, tradução nossa)

Entretanto, mesmo sendo defensores da utilização do método matemático na economia, foram bastante prudentes sobre a abrangência e generalidade quantitativa no estudo do comportamento humano. Eles deixam claro que primeiramente era necessário estudar problemas mais simples quanto a questões 
de tomada de decisão, para depois propor avanços mais complexos:"O grande progresso em cada ciência vem quando, no estudo dos problemas que são modestos comparados aos objetivos finais, desenvolvem-se métodos que permitem o progresso contínuo" (Von Neumann; Morgenstern, [1944] 1980, p. 6, tradução nossa).

Ademais, é fundamental lembrar que, para os autores, "risco" e "incerteza" se distinguem. O primeiro pode ser avaliado pela frequência de eventos observados, já o segundo corresponde a uma avaliação subjetiva do evento, em que os eventos passados (as experiências passadas dos indivíduos) representam elementos indispensáveis.

Segundo Menezes (2012), é assim que dois conceitos distintos (risco e incerteza) são confundidos nos desdobramentos da escola neoclássica: tendo o risco como principal característica, "a existência de uma frequência de eventos", e a incerteza "não dispor de frequência"; mas trata-se de uma probabilidade subjetiva; desde que se possa construir uma distribuição de probabilidade sobre as consequências da decisão, risco e incerteza se confundem e podem ser avaliados como iguais (Menezes, 2012).

Na leitura de Kast (1993), é por essa razão que se torna essencial, em cenários de risco e incerteza, que o comportamento do agente em processos decisórios seja determinado pelo viés da racionalidade, isto é, que tenha preferências bem definidas e compatíveis com uma distribuição de probabilidade.Tais distribuições foram definidas porVon Neumann e Morgenstern como sendo "loterias" - mesmo os resultados não sendo derivados de experimentos aleatórios - como forma de, nessas circunstâncias, o agente racional parametrizar suas decisões pela ótica maximizadora de satisfação (ou utilidade esperada da loteria). Assim sendo, são desenvolvidas pelos autores antes citados, normas de comportamento dos agentes em situações de escolhas, em que o agente racional reconhece esse padrão (de comportamento) e decidir-se-á de maneira subordinada a tal padrão axiomático. É nesse contexto queVon Neumann e Morgenstern elaboram um conjunto de premissas envolvendo preferências e probabilidade, o que conhecemos hoje como axiomas da teoria da utilidade esperada, ou axiomas deVon Neumann e Morgenstern;"'os axiomas promulgam as condições de preferências dos agentes de modo a serem representadas por uma função numérica" (Varian, 2006, p. 37).

Tais pressupostos axiomáticos são a base para a análise do comportamento do agente racional em situações decisórias diante do risco e da incerteza, além de integrarem diversos trabalhos neoclássicos em distintas linhas de pesquisa 
dentro da própria economia. Entre os muitos trabalhos que buscaram aprimorar essa discussão, encontram-se o trabalho de Savage (1954), e de tantos outros. ${ }^{9}$

Desse modo, não podemos dizer que há um único modelo dentro da teoria econômica neoclássica que busca explicar a tomada de decisão dos agentes. Há, sim, diversos modelos que utilizam a máxima de racionalidade dos agentes - muitas vezes chamados de consumidores pela escola neoclássi$\mathrm{ca}-\mathrm{e}$ os pressupostos axiomáticos para explicar o comportamento dos agentes em tomadas de decisões.

Entre estes, existe um modelo dito "básico" que busca explicar as ações dos agentes em um "mundo sem incerteza", e que se apropria de dois axiomas, a saber: completude e transitividade. Esses dois axiomas (padrões de comportamento), dentro do modelo, garantem a cada agente (que escolhe) um conjunto de opções, que faz com que esse agente seja capaz de ordenar suas opções com base em suas preferências, ${ }^{10} \mathrm{e}$ assim possa tomar a melhor decisão possível.

Em cenários que envolvem incerteza, no entanto, uma análise mais complexa é proposta pela teoria neoclássica e deriva-se do modelo de Savage (1954). A explicação desse modelo se faz pela probabilidade subjetiva, formalizada matematicamente e que resulta na seguinte função utilidade: ${ }^{11}$

$$
\max \sum_{t=0}^{\infty} \partial^{t} \sum_{s_{t} \in s_{t}} p\left(s_{t}\right) U\left(x_{t i} \mid s_{t}\right)
$$

A função descrita refere-se à função da utilidade esperada do modelo de Savage e busca, por meio da utilização dos pressupostos de maximização de utilidade esperada e formação de expectativa subjetiva bayesiana, ${ }^{12}$ representar a racionalidade dos agentes que tomam decisões, ou seja, que escolhem.

Esse modelo, mais completo, que envolve tomada de decisão e incerteza e que podemos chamar de "modelo padrão", pressupõe três alternativas: i) um conjunto de estados alternativos do mundo que estão além do controle

\footnotetext{
${ }^{9}$ Dentre os diversos trabalhos que buscaram ampliar a discussão do padrão racional de comportamento dos agentes, podemos citar: Allais (1953) e Ellsberg (1961).

${ }^{10}$ A discussão sobre preferências e os axiomas completude e transitividade pode ser encontrada em Varian (2006).

${ }^{11} \mathrm{O}$ modelo formalizado matematicamente e as exposições dos respectivos pressupostos estão baseados nos trabalhos de Wilkinson e Klaes (2012), e também podem ser encontrados em Castro (2014).

${ }^{12}$ A expectativa subjetiva bayesiana é derivada do Teorema de Bayes. Esse teorema objetiva explicar um tipo de inferência estatística (inferência bayesiana), que descreve as incertezas sobre quantidades invisíveis de forma probabilística. Assim, as incertezas são modificadas periodicamente após observações de novos resultados.
} 
do tomador de decisão, ou seja, situações conjunturais ou de ambiente que estão fora do controle dos agentes que decidem; ii) um conjunto fixo de alternativas disponíveis, isto é, alternativas limitadas; iii) um conjunto de consequências alternativas. A escolha da alternativa determinará as possíveis consequências em cada "estado do mundo", de tal modo que, para cada alternativa, o agente calculará o produto da probabilidade dos estados do mundo $\left[p\left(s_{t}\right)\right]$ por meio da utilidade das consequências associadas, de maneira que, adicionandos todos os produtos, o agente obtém a utilidade esperada da alternativa. A função de utilidade $\left[U\left(x_{t i} \mid s_{t}\right)\right]$ se define pelas consequências das alternativas escolhidas pelo agente $\left[x_{t i}\right]$; dessa forma, dado o estado do mundo $[s]$, a utilidade futura é descontada por um fator temporal exponencial [ $\left.\partial^{t}\right]$, de modo que o agente, no período $t=0$, escolherá o vetor de alternativa (de ação corrente ou futura) de maior preferência dentre as disponíveis, isto é, que tenha a maior utilidade esperada (Castro, 2014). ${ }^{13}$

Desse "modelo padrão", originaram-se alguns pressupostos de comportamento do agente econômico neoclássico: i) os agentes são racionais; logo, têm preferências bem definidas; ii) têm preferências pelos estados finais e não pelas mudanças; iii) suas preferências se dão por suas crenças e informações; iv) suas informações são processadas de acordo com a probabilidade bayesiana (teorema de Bayes); v) são autointeressados, isto é, não consideram a utilidade dos outros agentes; vi) são maximizadores de utilidade esperada, ou seja, buscam sempre a otimização; vii) formam suas preferências temporais de acordo com um modelo de utilidade esperada.

Seguindo um raciocínio similar ao de Beckert e Dequech (2005) e já acordado por Castro (2014), o modelo de Savage pode ser interpretado como "modelo padrão" de comportamento do agente econômico racional, pois tem a capacidade de desempenhar três funções distintas: i) função descritiva - o modelo descreve como os agentes realmente se comportam em processos decisórios; ii) função prescritiva - o modelo sugere como os agentes deveriam se comportar para serem considerados racionais; iii) função preditiva - admite a obtenção, por meio de um modelo com "função-utilidade" e de probabilidade subjetiva, das decisões dos agentes econômicos, sem no entanto supor que os agentes realmente se comportem com base nesse modelo, de modo que resolve um complexo problema de otimização e de cálculo probabilístico (Castro, 2014).

\footnotetext{
${ }^{13}$ A ideia desenvolvida refere-se ao pressuposto de otimização ou maximização da utilidade esperada.
} 
Entretanto, vale salientar que, nas últimas décadas, inúmeros trabalhos teóricos e empíricos revelaram diversas limitações desse modelo. Os próprios economistas neoclássicos normalmente contestam dizendo que não são ingênuos a ponto de acreditar que os agentes se comportem da forma descrita pelo "modelo padrão". Nesse sentido, esse modelo seria usado somente para fins prescritivos e preditivos. Assim, segundo os teóricos neoclássicos, o modelo padrão serve para prever o comportamento econômico real dos indivíduos somente quando usando o argumento do tipo "seleção natural", isto é, os indivíduos seriam eficientes em perseguir seus objetivos se tivessem incentivos ou oportunidades de aprender com as experiências adquiridas. Além disso, os neoclássicos argumentam que a concorrência, por sua vez, favorece os indivíduos na medida que suas decisões ótimas aumentam suas chances de sucesso em um ambiente competitivo. Assim, uma minoria de agentes racionais pode ser capaz de impor racionalidade a todo um mercado. Desse modo, de acordo com a teoria neoclássica, seria razoável prever os resultados das escolhas "como se" elas fossem produto de um processo de otimização (Castro, 2014).

Esses pressupostos comportamentais, desenvolvidos dentro da teoria da utilidade, foram a base para o desenvolvimento de diversas linhas e estão presentes em muitos modelos de otimização até o presente momento. Entretanto, diversas outras linhas de pesquisa têm apontado inúmeras discrepâncias entre comportamento humano proposto pelo modelo neoclássicos e o comportamento humano real observado. Dentre essas linhas de pesquisa, uma que se encontra em evidência e desponta como fronteira do conhecimento dentro da teoria econômica é a "economia comportamental".

Nesse sentido, apresentaremos, na próxima seção, um breve desdobramento da crítica formulada pela ciência comportamental ao modelo padrão de comportamento neoclássico.

\section{A tomada de decisão mediante a subjetividade humana}

Segundo Earl (1988), a economia comportamental nasce entre as décadas de 1950 e 1960, sem essa definição, porém com características que se ajustam ao que hoje se convencionou chamar de economia comportamental. Segundo Kahneman (2011) e Wikinson e Klaes (2012), nesse período encontram-se obras de autores fundamentais no desenvolvimento da disciplina, 
como Katona e Fisher (1951) e Simon (1957), que naquele período apresentaram uma crítica veemente à teria da decisão, no que tange ao comportamento humano.

Katona e Fisher (1951, p. 93-94) argumentam que as mudanças no sistema econômico não poderiam ser explicadas exclusivamente pela síntese neoclássica. Segundo os autores, os agregados econômicos não eram explicados somente por meio das variáveis econômicas:"o estudo da macroeconomia sem psicologia apenas aponta as condições vigentes onde as ações dos indivíduos acontecem, porém, essas [ações] não podem ser tidas como homogêneas". Assim, segundo os autores, cada indivíduo age, reage, toma decisões de maneira distinta, dependendo de suas condições e aspirações pessoais, não estando exclusivamente dependentes dos agregados econômicos (emprego, renda, juros etc..). Desse modo, a avaliação (percepção) da realidade econômico-social de cada indivíduo se faz relevante na determinação das decisões individuais e do comportamento econômico geral.

Simon, diferentemente de Katona e Fisher, trata, de maneira mais específica, da tomada de decisão em contexto de incerteza e competição perfeita tanto no âmbito do indivíduo quanto das firmas. Faz uma crítica ao pressuposto da racionalidade dizendo:

[...] não pode haver dúvidas quanto aos pressupostos da teoria da racionalidade perfeita serem completamente opostos à realidade, visto que não descrevem, nem remotamente, os processos que os indivíduos utilizam na tomada de decisão em situações complexas. (Simon, 1978, p. 366, tradução nossa)

Assim, segundo o autor, as decisões do mundo real, que são cercadas de imperfeições e incertezas, não poderiam ser calculadas de maneira ótima, mas de maneira satisfatória. ${ }^{14}$ Desse modo, a racionalidade perfeita não existiria. E o termo deveria ser substituído por racionalidade limitada. ${ }^{15}$

Segundo Simon (1957, p. 199), “a capacidade da mente humana de formular soluções complexas é muito pequena comparada ao tamanho dos problemas expostos e solucionados pelo comportamento racional". Desse modo, para o autor, os indivíduos e as firmas tomam decisões de maneira distinta, não homogênea, porque suas decisões são pautadas por restrições cognitivas e de conhecimento do ambiente onde estão inseridos.

\footnotetext{
${ }^{14}$ Para maior detalhamento, ver Simon (1978).

${ }^{15}$ Para melhor detalhamento sobre racionalidade limitada, ler: Simon (1978).
} 
Entretanto, apesar de as críticas de Katona, Fisher e Sinom terem recebido muita atenção, foi somente na década de 1970 que efetivamente a teoria da decisão padrão começou a receber um enfrentamento teórico pujante (Comerer; Loewenstein, 2004).

Em um esforço de identificar as etapas do desenvolvimento da economia comportamental e a crítica a teoria da decisão padrão, Angner e Loewenstein (2006) apontam três fases que marcariam o desenrolar temporal e metodológico da disciplina. São elas: i) seu "nascimento" seria datado entre os anos de 1970 e 1980 com as primeiras publicações que tinham o objetivo de identificar "anomalias", ou seja, movimentos observados na economia que não podiam ser explicados pelo padrão de comportamento proposto pela teoria neoclássica; ii) posteriormente, entre as décadas de 1980 e 1990, a disciplina passa a incorporar os pressupostos comportamentais aos modelos econômico-matemáticos; iii) e a última fase é a incorporação dos pressupostos comportamentais à macro e microeconomia e a elaboração de políticas públicas.

Partindo dos modelos descritivos publicados por Kahneman e Tversky (1974), o método utilizado para identificar o comportamento da maioria dos agentes econômicos (individual e coletivo) passou a ser a observação de suas tendências de escolha ou vieses de comportamento.

Kahneman e Tversky (1979), buscam mostrar que os indivíduos normalmente fazem julgamentos (formam juízo de valor) e inferências baseados em princípios heurísticos, que facilitam a tarefa complexa de avaliar probabilidades e predizer valores a operações mais simples. Em uma crítica à utilização da probabilidade subjetiva feita pela moderna teoria da decisão ${ }^{16} \mathrm{e}$ aos axiomas da decisão racional da teoria neoclássica, os autores sustentam que os indivíduos em situações reais, do cotidiano, utilizam uma forma particular de estimativa de probabilidade em seus julgamentos que são baseados em dados e observações limitados e que são processados de acordo com "regras heurísticas".

Desse modo, os autores enumeram três heurísticas que são utilizadas pelos indivíduos ao avaliar probabilidades e prever valores. São elas:i) representatividade; ii) disponibilidade; ii) ajuste e ancoragem. Essas heurísticas apontam o surgimento de diversos vieses de comportamento nos processos de julgamento mediante a incerteza, tais como: insensibilidade à probabilidade a priori dos resultados; ilusão de validade; concepções errôneas de regressão;

${ }^{16}$ Como moderna teoria da decisão, os autores citam o trabalho de Savage (1954) 
viés de "imaginabilidade"; correlação ilusória; ajuste insuficiente, entre outros apresentados por diversos pesquisadores nas últimas três décadas.

De fato, a economia comportamental quebra com todo o rigor do pressuposto da racionalidade, pois coloca o indivíduo como um agente cuja subjetividade irá sempre interferir em seu processo de julgamento e decisão. Nesse sentido, uma "matematização" do comportamento individual deixa de ter sentido como análise primária. Dessa forma, o método de análise do processo de julgamento e decisão passa a incorporar experimentos sociais e psicológicos, com o objetivo de compreender quais as subjetividades estão por de trás de cada decisão.

\section{Considerações finais}

O comportamento humano diante de uma situação de escolha é tema extensamente abordado por diversos teóricos econômicos. No decorrer deste trabalho buscamos apresentar uma concisa revisão do tratamento dado à teoria da decisão por alguns dos autores mais lidos dentro das ciências econômicas.

Conforme apresentamos, a temática desde o princípio esteve fortemente atrelada ao desenvolvimento da teoria estatística, na qual a probabilidade passou a ser ferramenta capital na análise do processo de escolha. Entretanto, como toda reação vinculada a uma ação humana, a tomada de decisão passa por diversas limitações, como a incerteza e a subjetividade individual daquele que escolhe. Bernoulli, Jevons, Walras, Pareto, Hick, Allen, Von Neumann, Morgenstern, Savage e tantos outros pensadores que se debruçaram sobre essa temática sabiam disso. Contudo, como forma de mitigar a incerteza do porvir e de se aproximar de uma análise quantitativa, esses autores buscaram, no desenvolvimento de teorias, premissas e pressupostos, oferecer uma resposta a questões tão difíceis de serem respondidas: como o indivíduo se comporta? Como toma decisões?

Apesar de ampla aceitação às respostas oferecidas pela economia neoclássica, estas despertaram grandes inquietações. Alguns pesquisadores, insatisfeitos com o trato dado à incerteza e ao comportamento humano, buscaram analisar a tomada de decisão de forma mais subjetiva. Dentro da teoria econômica, não foram poucos os teóricos que questionaram o poder analítico e descritivo da teoria da decisão padrão. Knight, Keynes, Katona, Fisher e Simon, talvez tenham sido os mais ruidosos questionadores de suas épocas, de modo a 
oferecermos uma perspectiva diferente sobre o papel da incerteza e da subjetividade humana no processo decisório. Ora, se a incerteza e as subjetividades são algo que não pode ser mensurado nem calculado por formulação matemática e são intrínsecas à vida humana, elas se tornam parâmetros fundamentais que devem ser considerados na análise de qualquer processo decisório.

Essa quebra com as formulações matemáticas, estatísticas e de padronização do comportamento humano nas ciências econômicas foi fundamental para o avanço do pensamento, colaborando para a determinação de um novo campo de estudo dentro da economia: a economia comportamental.

As pesquisas na área de economia comportamental, buscam uma interconexão com a área de psicologia e, também, com outras áreas das ciências sociais, a fim de melhor compreender o comportamento individual. Aceitando que os seres humanos são únicos e reagem a determinadas situações de maneira distintas, conforme o ambiente em que estão inseridos e as situações de decisão a eles colocadas, as pesquisas na área da economia comportamental trazem à luz, na discussão sobre a tomada de decisão, vieses de comportamento presentes no processo de julgamento e decisão individual.

Desse modo, este trabalho não pretendeu esgotar o debate, mas objetivou apresentar alguns dos mais importantes autores dentro da escola econômica no que tange à teoria da decisão.

\section{Referências}

ALLAIS, M. Le comportement de l'homme rationnel devant le risqué: critique des postulats et axioms de l'ecole americaine. Econometrica, v. 21, n. 4, 1953.

ANGNER, E.; LOEWENSTEIN, G. Behavioral economics. Elsevier's Handbook of the Philosophy of Science, v. 5, 2006.

BARBIERI, F. Utilidade cardinal, mensurabilidade e a evolução do pensamento metodológico. XLI ENCONTRO NACIONAL DE ECONOMIA, 2014, Natal. Anais: XLI Encontro Nacional de Economia, 2014.

BECKERT, J.; DEQUECH, D. Risk and Uncertainty. In: BECKERT, J.; ZAFIROVSKI, M. (Org.) The Encyclopedia of Economic Sociology. Londres: Routledge, p. 578-587, 2005. 
BERNOULLI, D. (1738). Exposition of a new theory on the measurement of risk (Specimen theoriae novae de mensura sortis. Commentari academiae scientiarum imperialis petropolitanae). Econometrica, v. 22, n. 1, p. 23-36, 1954.

BERNSTEIN, P. L. Against the gods: the remarkable story of risk. NewYork: John Wiley \& Sons, 1996.

CARVALHO, F. C. Keynes on probability, uncertainty, and decision making. Journal of Post Keynesian Economics, v. 11, n. 1, 1998.

CASTRO, A. S. R. Economia comportamental: caracterização e comentários críticos. Campinas: Unicamp, 2014 (Dissertação de Mestrado em Economia da Unicamp).

COMERER, C.; LOEWENSTEIN, G. Behavioral economics: past, present and future. In: CAMERER, C. et al. M.Advances of Behavioral Economics. Princeton: Princeton University Press, 2004.

CUSINATO, R.T. Teoria da decisão sob incerteza e a hipótese da utilidade esperada: conceitos analíticos e paradoxos. Porto Alegre: UFRGS, 2003 (Dissertação de Mestrado em Economia da UFRGS).

DAVID, F. N. Games, God, and Gambling. New York: Hafner Publishing Company, 1962.

DAVIDSON, P. Uncertainty in economics. In: DOW, S.; HILLARD. J. Keynes, knowledge and uncertainty. Aldershort: E. Elgar, p. 201-222, 1995.

DEQUECH, D. Fundamental uncertainty and ambiguity. Eastern Economics Journal, v. 26, n. 1, p. 41-60, 2000.

DEQUECH, D. Neoclassical, mainstream, orthodox, and heterodox economics. Journal of Post Keynesian Economics, v. 30, p. 279-302, 2007.

DEQUECH, D. Uncertainty in a strong sense: Meaning and sources. Economic Issues, v. 2, n. 2, p. 21-43, 1997. 
DEQUECH, D. Uncertainty: individuals, institutions and technology. Cambridge Journal of Economics, v. 28, n. 3, p. 365-378, 2004.

DIAS, M. C. L. C. Uma reconstrução racional da concepção utilitarista de Bentham: os limites entre a ética e a legislação. São Paulo: USP, 2006 (Dissertação de Mestrado em Filosofia da USP).

EARL, P. Behavioral Economics. Aldeshort: Edward Eldar, 1988.

EDGEWORTH, F.Y. Mathematical psychics: an essay on the application of mathematics to the moral sciences. London: C. Kegan Paul, 1881.

ELLSBERG, D. Nations of measurable utility. The Economic Journal, v. 64, p. 528-556, 1954.

FERGUSON, C. E. Teoria Microeconômica. Rio de Janeiro: Ed. Forense, 1992.

GOSSEN, H. H. (1854). Entwicklung der gesetze des menschlichen verkehrs und der daraus fliessenden regln für menschliches handeln, Berlin: R. L. Prager, 1927.

HICKS, J. R.; ALLEN, R. G. D. A reconsideration of the theory of value. Economics, New Series, v. 1, n. 2, p. 52-76, 1934.

HUGON, P. História das doutrinas econômicas. São Paulo: Atlas, 1995.

JEVONS, W. S. (1871). A teoria da economia política. São Paulo: Nova Cultural, 1996.

KAHNEMAN,D. Thinking, fast and slow. NewYork: Farrar, Straus and Giroux, 2011.

KAHNEMAN, D.;TEVERSKY, A. Prospect theory: an analysis of decision under risk. Econometrica, v. 47, n. 2, 1979.

KAHNEMAN, D.; TVERSKY, A. Judgment under uncertainty: heuristics and biases. American Psychological Association, v. 185, n. 4157, 1974.

KAST, R. La théorie de la decision. Paris: La découverte, 1993. 
KATONA, G.; FISHER, J. A. Post-war changes in the income of identical consumer units. NBER-Studies in income and wealth, n. 18, p. 62-122, 1951.

KEYNES, J. M. The general theory of employment, interest and money. New York: Harcout, 1936.

KEYNES, J. M. The general theory of employment. The Quarterly Journal of Economics, v. 51, n. 2, p. 209-255, 1937.

KNIGHT, F. H. (1921). Risk, uncertainty e profit. New York: Century Press, 1964.

LAPLACE, P. S. (1814). Concerning probability. In: NEWMAN,J. R. The world of mathematics: a small library of the literature of mathematics from A'h-mosé the scribe to Albert Einstein.Washington:Tempus Press, p. 1303-1308, 1988.

LAWSON, T. Economics and reality. London: Routledge, 1997.

MENEZES, W. F. Escolha e decisão em situação de incerteza e ricos. Revista Nexos, v. 5, n. 9, p. 59-105, 2012.

MENGER, C. (1871). Principles of Economics. Auburn: Ludwig von Mises Institute, 2007.

PARETO,V. (1906). Manual de economia política. São Paulo: Nova Cultural, 1996.

RUNDE, J. Chances and choices: Some note on probability and belief in economic theory. The Monist, v. 78, n. 3, p. 330-351, 1995.

RUNDE, J. Keynesian uncertainty and the instability of beliefs. Review of Political Economy, v. 3, n. 2, p. 125-145, 1991.

RUNDE, J. Keynesian uncertainty and the weight of arguments. Economics and Philosophy, v. 6, p. 275-292, 1990. 
SAVAGE, L. J. The foundations of Statistics. New York:Wiley, 1954.

SHACKLE, G. L. S. A scheme of economic theory. Cambridge: Cambridge University Press, 1965.

SHACKLE, G. L.S. Time, expectations and incertainty in economics. Selected essays. Aldershort: E. Elgar, 1990.

SIMON, H. A. Models of man: social and rational. Mathematical essays of rational human behavior in society setting. New York: Wiley, 1957.

SIMON, H. Rationality as process and as product of thought. The American Economic, v. 68, n. 2, p. 58-77, 1978.

VARIAN, H. R. Microeconomia: princípios básicos. São Paulo: Campus, 2006.

VIRCELLI, A. From soft uncertainty to hard environmental uncertainty. Economie Appliquée, v. 48, n. 2, p. 273-300, 1995.

VIRCELLI,A. Uncertainty, rationality and learning a Keynesian perspective. In: DOW, S.: HILLARD, J. Keynes, uncertainty and the global economy. Cheltenham: E. Elgar, p. 1-19, 2002.

VON NEUMANN, J.; MOR GENSTERN, O. (1944). Theory of games and economic behaviour. New Jersey: Princeton University Press, 1980.

WALRAS, L. (1874). Compêndio dos elementos de economia política pura. In: Os economistas. São Paulo: Nova cultura, p. 17-38, 1996.

WALRAS, L. Éstude d'économie politique aplliquée. Paris: Chez Pichon, 1898.

WILKINSON, N.; KLAES, M. An introduction to behavioral economics. London: Palgrave Macmillan, 2012. 